\title{
State of the Art in the Treatment of Gastrointestinal Stromal Tumors
}

\author{
Benjamin Garlipp Christiane J. Bruns \\ Klinik für Allgemein-, Viszeral- und Gefässchirurgie, Universitätsklinikum Magdeburg, \\ Magdeburg, Germany
}

\section{Key Words}

Gastrointestinal stromal tumor · Risk classification · Surgery · Treatment standards · Tyrosine kinase inhibitors

\begin{abstract}
Background: Gastrointestinal stromal tumors (GISTs) are the most frequently diagnosed mesenchymal neoplasms of the gastrointestinal tract. Despite their biological and clinical heterogeneity, the majority of these tumors are positive for the receptor tyrosine kinase KIT and are driven by KIT- or platelet-derived growth factor receptor alpha (PDGFRA)-activating mutations. There are still uncertainties regarding their clinical and molecular characterization and the optimal treatment regimens, making it difficult to establish a universal treatment algorithm for these tumors. Summary: From a clinical perspective, the main difference between GISTs and other gastrointestinal neoplasms is that the benign or malignant behavior of GISTs cannot be predicted from histopathology, but instead relies on empirically established scoring systems. Clinical data suggest that malignant potential may be an inherent quality of some GISTs rather than a feature acquired by the tumor during disease progression. Thus, some patients may require prolonged anti-tumor treatment even after complete surgical removal of the tumor. Key Message: Although GISTs are the most frequently occurring mesenchymal neoplasms in the gastrointestinal tract, no universal treatment algorithms exist. This paper reviews the current evidence that guides the management of GISTs. Practical Implications: The management of localized GISTs involves the use of surgical resection, with the inclusion of preoperative tyrosine kinase inhibitor treatment for locally advanced, primarily unresectable tumors and for resectable cases requiring extensive surgery. Imatinib is also indicated as adjuvant therapy after complete surgical removal of GISTs with a high estimated risk of recurrence unless specific mutations conferring imatinib resistance are present. The optimal duration of adjuvant treatment is still controversial. For patients with metastatic imatinib-sensitive GISTs, imatinib constitutes the first-line standard treatment. Molecular characterization of the
\end{abstract}


Garlipp and Bruns: State of the Art in the Treatment of Gastrointestinal Stromal Tumors

tumor (with respect to the PDGFRA and KIT genes) is mandatory prior to imatinib therapy. Sunitinib and regorafenib are established as alternative treatments for patients demonstrating generalized disease progression on imatinib. New tyrosine kinase inhibitors such as ponatinib and crenolanib as well as drugs targeting alternative pathways are currently under investigation. Surgery and locally ablative treatments may be indicated in some metastatic patients.

(C) 2015 S. Karger AG, Basel

\section{Introduction}

Historically, the term 'gastrointestinal stromal tumor (GIST)' was used to describe gastrointestinal neoplasms classified as leiomyoma, leiomyosarcoma or leiomyoblastoma by light microscopy, but demonstrating ultrastructural and immunohistochemical features that suggested non-smooth muscular origin of these lesions [1]. When it was discovered in 1998 that virtually all of these tumors were immunohistochemically positive for the receptor tyrosine kinase KIT (CD117) and had mutations in the KIT gene that lead to ligand-independent, constitutive activation of that kinase $[2,3]$, these characteristics were soon recognized as their principal tumorigenic mechanism. 'GIST' has ever since been used to describe mesenchymal gastrointestinal neoplasms that are KIT-positive and driven by KIT- or plateletderived growth factor receptor alpha (PDGFRA)-activating mutations, although there remains a small proportion of GISTs that do not demonstrate these properties and for which alternative pathogenetic mechanisms must be assumed. Expression of KIT is also essential for the development of the pacemaker system of gastrointestinal motility formed by the interstitial cells of Cajal, which is why GISTs are thought to derive from pluripotent precursor cells that normally differentiate into interstitial cells of Cajal. From a clinical perspective, GISTs are extremely heterogeneous. They may arise in the entire gastrointestinal tract between the lower esophagus and the anal canal. The principal difference to other gastrointestinal neoplasms is that benign or malignant behavior of GISTs is impossible to predict from histopathology. The spectrum extends between GISTs that remain indolent throughout life without ever requiring a therapeutic intervention and GISTs developing rapid multifocal dissemination in spite of intensified multidisciplinary treatment. So far, therapeutic decisions largely rely on empirically established scoring systems intended to predict the malignancy risk. The medical treatment of GISTs has been revolutionized by the introduction of the tyrosine kinase inhibitor (TKI) imatinib mesylate (Glivec ${ }^{\circledR}$ ) [4]; however, most patients develop secondary drug resistance within 2 years after initiation of treatment $[5,6]$. Moreover, the molecular characteristics of GISTs may confer differences in imatinib sensitivity. The clinical heterogeneity and complexity of GISTs make it difficult to establish universal treatment algorithms, and the management of these tumors is generally highly individualized, taking into account patient characteristics, morphological and molecular tumor features and clinical behavior of the disease on follow-up exams. This review summarizes the current status of GIST management, specifically focusing on controversial issues in the combined use of local and systemic treatment approaches in individual patients.

\section{Epidemiology}

While GISTs were formerly regarded as rare tumors, the definition of histomorphological and immunohistochemical criteria for their diagnosis has made it clear that many neoplasms once classified as smooth muscle cell or nerve sheath tumors by light microscopy are actually GISTs. Today, GISTs are the most frequently diagnosed mesenchymal gastrointestinal tumors, 
with a reported annual incidence of 10-20 cases per million [7-9]. These figures probably underestimate the true incidence as subclinical, small gastric GISTs are found in up to $25 \%$ of patients in gastrectomy specimens and in autopsy series $[10,11]$. Patients aged $>50$ years predominate among individuals diagnosed with GISTs (median age at diagnosis 60-65 years); however, GISTs may develop at any age. GISTs developing in patients $<40$ years frequently do not demonstrate activating KIT or PDGFRA mutations; instead, loss-of-function mutations in the succinate dehydrogenase (SDH) complex are found with increased frequency in this population $[12,13]$. Clinically and morphologically, these tumors differ from GISTs with KIT or PDGFRA mutations in that they are generally restricted to the stomach, are less responsive to treatment with known TKIs and show a greater propensity for developing lymphovascular invasion and lymph node metastases [14]. Familial GIST syndrome caused by germline mutations in the KIT or PDGFRA gene has been reported [15-17]. Syndromal development of GISTs that are generally negative for KIT- or PDGFRA-activating mutations and preferentially located in the small intestine occurs in patients with neurofibromatosis type 1 (NF-1) [18, 19]. Similar to sporadic GISTs, the true incidence of NF-1-associated GISTs is probably underestimated as they are frequently found in autopsy studies. Clinically, these tumors are also characterized by their poor response to imatinib [18].

\section{Diagnosis}

The common clinical manifestations of GISTs include gastrointestinal bleeding, abdominal discomfort and ulcer-like symptoms. However, up to $30 \%$ of GISTs are asymptomatic and are diagnosed as an incidental finding during endoscopic screening or imaging procedures. In patients presenting with signs of chronic gastrointestinal hemorrhage, upper and lower gastrointestinal endoscopy are usually the initial diagnostic steps. However, small intestinal GISTs may not be amenable to standard endoscopic examination, and advanced endoscopic techniques (double-balloon enteroscopy and/or capsule endoscopy) may be required in these cases [20-23]. For treatment planning purposes, endoscopic assessment of GISTs should be complemented by cross-sectional imaging in all patients. Contrast-enhanced computed tomography (CT) and magnetic resonance imaging (MRI) are both used to evaluate the extent of the primary tumor as well as its relation to adjacent organs and to detect gross metastatic disease. Moreover, CT and MRI imaging criteria have been described to help differentiate GISTs from other gastrointestinal tumors $[24,25]$ and to estimate their malignant potential $[26,27]$, although these need to be validated in larger trials.

Unguided endoscopic biopsy of subepithelial masses suspected to be GISTs is successful in yielding a definite diagnosis in only $20-30 \%$ of cases. For higher diagnostic accuracy, tissue acquisition for histopathological examination should be performed using endoscopic ultrasound-guided fine needle aspiration (EUS-FNA) [28, 29]. In one study [30], endoscopic ultrasound-guided core needle biopsy was able to yield an accurate histomorphological and immunohistochemical diagnosis in 79 and $97 \%$ of cases, respectively, in patients in whom EUS-FNA had previously been unsuccessful. Moreover, obtaining a true tissue sample by core needle biopsy rather than a cluster of cells by FNA may facilitate further treatment planning because a mitotic count, which is crucial for metastatic risk assessment, may not be reliably performed on an FNA specimen. However, the smaller the suspicious lesion, the more difficult it will turn out to acquire adequate tissue for histological examination. For subepithelial gastric lesions $<2 \mathrm{~cm}$ in diameter, it may therefore be acceptable to perform regular follow-up without a histological diagnosis and to postpone further diagnostic or therapeutic intervention until progression is observed. As discussed above, small, subclinical gastric GISTs are a common finding in gastrectomy specimens and in autopsy series and very likely have no prognostic 
relevance. Alternatively, if the location of the lesion is favorable and complete surgical excision is feasible with low morbidity, it may be performed without having obtained a prior tissue diagnosis after discussing the risks and benefits with the patient. Obtaining a histological diagnosis is also not mandatory in larger lesions if upfront surgery is clearly indicated based on imaging findings. If a preoperative tissue diagnosis is required (e.g. if complete removal of the lesion necessitates extensive surgery, if a gastrointestinal lymphoma that should not be treated surgically is suspected, or if preoperative imatinib treatment is discussed), tissue acquisition should also be preferentially performed via the endoluminal route. For lesions not amenable to endoscopic ultrasound-guided biopsy, CT-, MRI- or ultrasound-guided percutaneous biopsy may be an alternative but must be executed with caution to prevent tumor spillage [31, 32].

${ }^{18} \mathrm{~F}$-fluorodeoxyglucose positron emission tomography (FDG-PET) has a limited role in the primary diagnosis of GISTs. Tracer substances that are specific for GISTs (e.g. radiolabelled antibodies directed against KIT or other surface antigens of GIST cells) have been tested in preclinical models, but none of them has been introduced into clinical use yet [33, 34]. However, FDG-PET plays an important role in situations where early assessment of response to TKI treatment is necessary [35] (see below).

\section{Management of Localized GISTs}

\section{Surgery}

Complete surgical removal is the mainstay of treatment for localized gastric GISTs $>2 \mathrm{~cm}$ and for extragastric GISTs of any size. Following surgery, 15-year disease-free survival is $59.9 \%$ according to a pooled analysis of 10 population-based series comprising 2,560 patients. Tumor recurrence later than 10 years is extremely rare. Thus, approximately $60 \%$ of patients with GISTs are cured by surgery [36]. Controversial data exist as to the issue of the prognostic relevance of surgical margins. While complete, margin-negative (R0) tumor excision remains the goal of GIST surgery and an increased recurrence rate might be expected following resection with tumor-involved margins, this was not confirmed in all studies $[37,38]$. Therefore, if examination of the surgical specimen reveals microscopically tumor-positive margins, reoperation should only be attempted if the original site of the involved margin can be identified and its excision does not cause major functional sequelae and is not associated with undue operative risk; however, the paucity of data regarding this issue makes this decision a highly individual one.

Surgical procedures according to tumor site include local gastric wall excision, segmental gastric resection and gastrectomy for gastric GISTs, transhiatal or, rarely, transthoracic lower esophageal resection for esophageal GISTs, segmental resection for small intestinal GISTs, and transanal excision, anterior rectal resection or abdominoperineal rectal excision for rectal GISTs. Multivisceral resections may become necessary in case of involvement of adjacent organs, as can be the case with duodenal GISTs, which may require pancreatoduodenectomy; however, as in all patients requiring major functionally impairing surgery for complete tumor removal, tumor shrinkage through neoadjuvant imatinib treatment should be attempted in these cases to facilitate resection and possibly enable organ-preserving surgery (see below) $[39,40]$.

As GISTs rarely metastasize into regional lymph nodes [41, 42], systematic lymph node dissection is usually not required. Excision of regional lymph nodes may be considered in patients $<40$ years who often have SDH-deficient GISTs and are thus more prone to developing lymphovascular invasion and lymph node metastases [14]; however, lymphatic tumor spread was not identified as an adverse prognostic factor in retrospective studies [13]. The 
benefit of systematic lymph node dissection in juvenile, SDH-deficient GISTs has never been prospectively evaluated, and lymphadenectomy should only be attempted if it does not lead to undue extension of the procedure with increased morbidity or functional impairment.

As limited resections are often adequate in localized GISTs, laparoscopic surgery may be a valuable alternative to open resection. The feasibility of laparoscopic surgery for GISTs has been demonstrated in numerous series [43-46]. In a recent retrospective analysis of patients treated by laparoscopic resection of GISTs between 2002 and 2012, the 5-year recurrencefree survival was $63 \%$ in high-risk patients whereas it was $100 \%$ at 10 years in the low- and very-low-risk groups, indicating that laparoscopic surgery may be performed with similar results as open resection [47]. A recent meta-analysis of 22 studies comparing laparoscopic versus open surgery for GISTs including 1,166 patients demonstrated improved short-term results (intraoperative blood loss, onset of gastrointestinal motility, time to oral intake, hospital stay and overall complications) in the laparoscopic group [48]. However, one of the major pitfalls of surgery for GISTs is the risk of intraoperative tumor rupture, conferring a recurrence rate of almost 100\% [49]. Since the risk of tumor rupture increases with tumor size and may be elevated in tumors with an unfavorable location, laparoscopic surgery should be restricted to easily accessible lesions and is not recommended for large lesions (usually $>5 \mathrm{~cm}$ ), although this strongly depends on individual surgical expertise and laparoscopic resection has been demonstrated to be feasible even in large GISTs in single-center series $[46,50]$.

Transluminal endoscopic resection techniques have been described for small GISTs [5153]. Since GISTs arise from the muscularis propria layer, established endoscopic resection techniques in the upper gastrointestinal tract (endoscopic mucosal resection, endoscopic submucosal dissection) can be expected to be associated with an increased risk of incomplete resection. Endoscopic full-thickness resection of the gastric wall has also been demonstrated to be feasible in single-center series [54,55], but as long as methods for postinterventional gastric wall closure are not standardized, these techniques must be considered as experimental. In contrast to gastric GISTs, transanal excision via transanal endoscopic microsurgery may be a safe alternative to transabdominal resection in small rectal GISTs [56-58].

\section{Preoperative Treatment}

In patients with locally advanced, inoperable but non-metastatic GISTs as well as in patients with operable tumors that require extensive, functionally impairing surgery or a procedure associated with substantial morbidity for complete removal, preoperative treatment with the aim to shrink the tumor and enable less radical surgery is indicated. In contrast to other solid gastrointestinal malignancies such as rectal cancer or liver metastases from colorectal cancer, there are no data to indicate that neoadjuvant treatment reduces the local or distant recurrence rate in easily resectable GISTs, and these should be treated by upfront surgery.

The overwhelming success of treatment with imatinib in metastatic GISTs [4, 59], achieving response or disease stabilization in $80 \%$ of cases in a disease that had previously been considered largely chemotherapy-refractory, prompted investigation of this drug in a perioperative setting. In most patients a substantial reduction in tumor size can be observed within 2-8 months of treatment. In a Dutch multicentric retrospective study of 57 patients with locally advanced GISTs, neoadjuvant treatment with imatinib achieved almost 50\% tumor size reduction, leading to successful R0 resection in $84 \%$ of patients [60]. In a prospective phase II study, imatinib was administered to 41 patients with locally advanced, non-metastatic GISTs. Less radical surgery was enabled by preoperative treatment in 26 patients and 3-year progression-free survival was 85.2\% [61]. Similar results were demonstrated in a pooled analysis of 161 patients from 10 sarcoma centers treated with preoper- 
Garlipp and Bruns: State of the Art in the Treatment of Gastrointestinal Stromal Tumors

ative imatinib for a median of 40 weeks, achieving R0 resection in $83 \%$ and 5-year diseasefree survival in $65 \%$. In a study evaluating combined neoadjuvant and adjuvant use of imatinib in patients with GISTs, R0 resection was achieved in 21 of 31 patients who had primary, locally advanced GISTs, with $23.8 \%$ of these developing recurrence at a median follow-up of 5.1 years. Taking these results together, it appears to be safe to perform less radical surgery if the tumor is downsized by preoperative treatment rather than upfront radical resection, although these two approaches have not been prospectively compared. GISTs of the rectum have a tendency to frequently require multivisceral resection or abdominoperineal excision, given the limited space within the pelvic cavity and the generally more aggressive course of this disease. Thus, preoperative downsizing to limit the extent of surgery may be particularly beneficial in these patients. In a study of 38 non-metastatic rectal GIST patients of whom 21 received preoperative imatinib, more patients in the preoperative imatinib group achieved R0 resection even though they had larger tumors at diagnosis than patients undergoing upfront surgery [62]. Given that most rectal GISTs also have a KIT exon 11 mutation that makes them sensitive to imatinib, some authors recommend preoperative imatinib treatment rather than upfront surgery for most patients with rectal GISTs.

Whenever neoadjuvant imatinib therapy is considered, the diagnosis of GIST must be clearly established and a mutation conferring primary imatinib resistance must be ruled out to avoid ineffective treatment and tumor progression, possibly leading to unresectability of a previously resectable lesion. In rare cases where a locally advanced GIST is suspected on imaging but obtaining a histopathological diagnosis including mutational analysis is not feasible or associated with considerable risk, a possible alternative may be to start imatinib treatment using early assessment of treatment response by FDG-PET imaging. Metabolic response seen on FDG-PET as early as 1-2 weeks after initiation of treatment has been demonstrated to accurately predict CT morphological response occurring at 8-week follow-up [6365]. Thus, patients with lesions that do not demonstrate major reduction in FDG uptake after 1-2 weeks of imatinib treatment should not continue to receive the drug and undergo definite histopathological assessment or upfront surgery.

\section{Adjuvant Treatment}

ACOSOG Z9001 was the landmark trial establishing the use of imatinib as adjuvant therapy in patients following complete surgical removal of GISTs [66]. 713 patients were randomly assigned to receive imatinib $400 \mathrm{mg}$ daily or placebo for 1 year following complete resection of primary GISTs $>3 \mathrm{~cm}$ in size. Patients developing recurrence in the placebo arm were offered crossover to imatinib. Recurrence-free survival was significantly improved in the imatinib arm (hazard ratio 0.35 ) whereas overall survival was not different between the two arms. This trial led to regulatory approval of adjuvant imatinib by the US and European authorities in 2008 and 2009, respectively. Given the potential toxicity associated with imatinib as well as the considerable cost of this treatment, identification of patients deriving benefit from adjuvant imatinib therapy remains a crucial issue. Data from retrospective studies were able to identify three clinical factors associated with the risk to develop tumor recurrence following resection of primary GISTs: anatomic site (GISTs of the stomach generally have a lower recurrence risk than extragastric GISTs), tumor size and mitotic rate. The Armed Forces Institute of Pathology (AFIP) classification of recurrence risk based on these criteria has since been used to select patients for adjuvant treatment [67] (table 1). Modified National Institutes of Health (NIH) criteria also acknowledge the AFIP criteria and incorporate tumor rupture as an independent feature placing a patient at high risk for tumor recurrence regardless of tumor size, anatomic site or mitotic count [68].

Despite significant improvement of recurrence-free survival with adjuvant imatinib in ACOSOG Z9001, that study also demonstrated that withdrawal of imatinib in the experi- 
Table 1. Prognosis of GISTs according to the AFIP criteria (from [67])

\begin{tabular}{|c|c|c|c|c|}
\hline \multicolumn{3}{|c|}{ Tumor parameters } & \multicolumn{2}{|c|}{$\begin{array}{l}\text { Patients with progressive disease during follow-up and } \\
\text { characterization of malignant potential, } \%\end{array}$} \\
\hline group & size, $\mathrm{cm}$ & $\begin{array}{l}\text { mitotic rate per } \\
50 \text { HPFs }\end{array}$ & gastric GISTs & small intestinal GISTs \\
\hline 1 & $\leq 2$ & $\leq 5$ & 0 / very low if any & 0 / very low \\
\hline 2 & $>2$ to $\leq 5$ & $\leq 5$ & 1.9 / low & 4.3 / low \\
\hline $3 a$ & $>5$ to $\leq 10$ & $\leq 5$ & 3.6 / low & $2.4 /$ intermediate \\
\hline $3 b$ & $>10$ & $\leq 5$ & 12 / intermediate & 52 / high \\
\hline 4 & $\leq 2$ & $>5$ & 0 / low* & 50 / high* \\
\hline 5 & $>2$ to $\leq 5$ & $>5$ & 16 / intermediate & 73 / high \\
\hline $6 a$ & $>5$ to $\leq 10$ & $>5$ & 55 / high & 85 / high \\
\hline $6 b$ & $>10$ & $>5$ & 86 / high & 90 / high \\
\hline
\end{tabular}

HPFs = High-power fields.

* Based on very small numbers insufficient for prediction of malignant potential.

mental arm was generally followed by a marked increase in recurrences after approximately 6 months. 12 months after imatinib was stopped (24 months after study entry), recurrence rates were largely similar in the imatinib and placebo arms, raising the question whether adjuvant imatinib should be given for a longer period. This was the rationale for the Scandinavian Sarcoma Group trial of adjuvant imatinib in resected GISTs (NCT00116935), randomizing patients with any high-risk feature (tumor diameter $>10 \mathrm{~cm}$, mitotic count $>10 / 50$ high-power fields, tumor diameter $>5 \mathrm{~cm}$ and mitotic count $>5 / 50$ high-power fields, or tumor rupture) to receive 1 vs. 3 years of adjuvant imatinib. The study demonstrated superior 5-year recurrence-free survival in the 3-year arm (65.6 vs. 47.9\%, hazard ratio 0.46$)$. At a relatively short follow-up of 54 months, 5 -year overall survival was also significantly improved with 3 vs. 1 year of imatinib ( 92.0 vs. 81.7\%, hazard ratio 0.45) [69]. Following these results, 3 years of adjuvant imatinib has become the treatment standard in patients with a high estimated risk of relapse following resection of a primary GIST as per current European Society for Medical Oncology (ESMO) and National Comprehensive Cancer Network (NCCN) guidelines [70, 71]. Again, a marked increase in recurrences was observed in both arms approximately 6 months after imatinib withdrawal, raising the question whether postoperative imatinib really decreases the probability of tumor recurrence in the long run (as would be expected from a truly adjuvant treatment) or rather postpones overt manifestation of a relapse that will occur anyway, being a palliative rather than an adjuvant treatment. Postoperative imatinib administration for 5 years is currently being evaluated in a phase II study (PERSIST-5, NCT00867113) and results are expected in 2016. However, in light of the observations from ACOSOG Z9001 and the Scandinavian study, indefinite continuation of treatment may be warranted for some patients. Further extension of postoperative imatinib treatment, however, requires more precise criteria for patient selection. Molecular tumor characteristics will likely play an important role in patient selection for adjuvant treatment in the future. While there is a consensus that patients demonstrating a PDGFRA exon 18 mutation that confers resistance to imatinib in the palliative setting (D842V) [72] should not receive adjuvant imatinib either, things are less clear for other molecular subtypes. A subgroup analysis of patients on the Scandinavian trial revealed no benefit of longer imatinib administration in patients demonstrating KIT exon 9 or any PDGFRA mutation, although these groups were small [69]. A recently published 
Garlipp and Bruns: State of the Art in the Treatment of Gastrointestinal Stroma Tumors

long-term follow-up analysis of patients on ACOSOG Z9001 [73] found that benefit from adjuvant imatinib in that study was basically accounted for by patients demonstrating deletions in KIT exon 11, whereas patients with insertions or point mutations in KIT exon 11, patients with KIT exon 9 mutations and patients with KIT/PDGFRA wild-type GISTs did not seem to derive benefit from adjuvant imatinib. In the absence of prospectively collected data, most oncologists will likely continue to offer adjuvant imatinib treatment to patients following resection of high-risk GISTs, except for those with a D842V mutation until more data become available; however, in light of this post hoc analysis, the decision has to be discussed in more detail with the patient if no KIT exon 11 mutation is present. For patients with a KIT exon 9 mutation, the above-mentioned analysis has to be interpreted with caution as patients in both the Z9001 and the Scandinavian trial uniformly received $400 \mathrm{mg}$ of imatinib daily, whereas a higher dose ( $800 \mathrm{mg}$ ) has been proven to be more effective in this cohort in the palliative setting [74]. While data in the adjuvant setting are lacking, offering $800 \mathrm{mg}$ per day as adjuvant treatment to patients with a KIT exon 9 mutation may be considered by extrapolation of these data.

\section{Management of Advanced/Metastatic GISTs}

\section{Medical Treatment}

Until the beginning of this century, GIST was generally regarded as a chemotherapyresistant disease, with response rates in the order of $0-5 \%$ and little to no improvement in survival with the use of conventional therapy [75]. The introduction of imatinib mesylate, a TKI that binds in a reversible manner to the adenosine triphosphate-binding pocket of KIT, PDGFRA and PDGFRB, has revolutionized the medical treatment of metastatic GISTs, achieving objective response in more than half of the patients and disease stabilization in over $80 \%$ [59]. Tumor response was likely underestimated in this initial trial as response was evaluated solely according to size-based criteria, whereas measurement of lesion density on CT is considered an essential component of response evaluation in GISTs by today's standards as it yields increased sensitivity compared to size-based criteria alone [76]. $400 \mathrm{mg}$ of imatinib per day constitutes the current first-line standard treatment for patients with metastatic GISTs unless they have a specific mutation in exon 18 of the PDGFRA gene (D842V) that has been demonstrated to confer resistance to imatinib [72]. In patients with a KIT exon 9 mutation, increasing the imatinib dose to $800 \mathrm{mg}$ per day has demonstrated a significant improvement in progression-free survival [74]. Hence, the higher dose should be given to patients with a proven exon 9 mutation who can tolerate it.

Despite initial treatment response, most patients develop secondary resistance to imatinib after a median of 2 years on treatment, essentially due to secondary mutations in the KIT or PDGFRA gene that interfere with drug binding $[5,77,78]$. Escalating the imatinib dose to $800 \mathrm{mg}$ per day in this progressing population was demonstrated to achieve response or disease stabilization in one third of patients in a recent systematic review of published data [79], and this approach is considered as the treatment standard by many oncologists, although all of the available evidence is based on retrospective, observational studies. Sunitinib, a multi-TKI active against KIT, platelet-derived growth factor receptors and vascular endothelial growth factor receptors, is the standard treatment for patients progressing on or intolerant to imatinib. In a study that randomized patients to receive either sunitinib $50 \mathrm{mg}$ daily on a 4 weeks on-/2 weeks off schedule or placebo, progression-free survival was 6.3 months in the sunitinib arm vs. 1.9 months in the placebo arm [80]. A recently published randomized controlled trial compared a novel TKI, masitinib, to standard-dose sunitinib in imatinib-refractory patients. Progression-free survival was 
3.71 months in the masitinib arm. Patients receiving sunitinib after progression on masitinib had longer overall survival compared to patients switching directly to sunitinib after imatinib failure in a secondary efficacy analysis [81], indicating that introducing a further line of therapy between imatinib and sunitinib may become an option as more data become available.

In patients progressing on both imatinib and sunitinib, imatinib rechallenge has been compared to best supportive care plus placebo in a randomized phase III trial. Progressionfree survival was doubled in the imatinib rechallenge arm, although the absolute progressionfree survival difference was only 0.9 months. There was no difference in overall survival, possibly due to the fact that $93 \%$ of patients on the placebo arm crossed over to imatinib upon progression [82]. Regorafenib, another orally available inhibitor of several tyrosine kinases approved in many countries for patients with metastatic colorectal cancer refractory to standard chemotherapy, was compared to placebo in patients with metastatic GISTs who were resistant to at least imatinib and sunitinib in the randomized phase III GRID trial [83]. Progression-free survival in the placebo arm was identical to the corresponding arm in the imatinib rechallenge trial ( 0.9 months), however, it was significantly prolonged to 4.8 months in the regorafenib arm. Overall survival was not different but, again, $85 \%$ of patients on the placebo arm crossed over to regorafenib upon progression, likely accounting for the lack in overall survival difference. This study led to regulatory approval of regorafenib for third-line treatment of metastatic GISTs and the drug can now be considered standard treatment for appropriate patients in this setting.

In all patients with metastatic GISTs, treatment should be continued indefinitely until disease progression or intolerance, even in the presence of sustained disease control. Interruption of imatinib treatment in patients with controlled disease invariably resulted in rapid progression, regardless of whether imatinib was withheld after 1, 3 or 5 years in the French Sarcoma Group BFR14 trial [84-86]. When imatinib was reintroduced in progressing patients, the vast majority responded again, but most patients did not achieve the remission status observed before imatinib interruption [87].

\section{Novel Agents}

A number of novel agents for the treatment of GISTs are currently under investigation, including TKIs, immunomodulating agents, heat shock protein inhibitors, a phosphoinositide 3-kinase inhibitor and an insulin-like growth factor 1 inhibitor. Among novel multikinase inhibitors, ponatinib might have the potential to become a new treatment option for patients refractory to all known TKIs. Ponatinib has demonstrated in vitro activity against a number of clinically relevant KIT mutants [88]. In a phase II study of 35 patients with refractory metastatic GISTs, roughly $50 \%$ of whom had progressed on all three established TKIs, ponatinib achieved response or disease stabilization in 55\% of patients with and $22 \%$ of patients without a primary KIT exon 11 mutation [89]. This study is still ongoing to enroll a total of 45 patients.

The management of metastatic patients demonstrating a PDGFRA exon 18 D842V mutation remains a particular challenge. In a preclinical model, more than 100 -fold enhanced activity against this specific mutation was demonstrated for crenolanib, an inhibitor of PDGFRA [90], compared to imatinib. A clinical trial to investigate crenolanib in D842V-mutant patients is currently ongoing.

KIT/PDGFRA wild-type GISTs constitute another entity that generally responds poorly to treatment with known TKIs. As these patients often have high expression of insulin-like growth factor 1 receptor (IGF-1R) due to deficient SDH function, linsitinib, a TKI with specific activity against IGF-1R, was investigated in a phase II study in this population [91]. No objective responses were observed, but 9-month progression-free survival was $52 \%$ with 
Garlipp and Bruns: State of the Art in the Treatment of Gastrointestinal Stromal Tumors

linsitinib. However, wild-type GISTs are heterogeneous and benefit from an anti-IGF-1R kinase inhibitor can only be expected for patients with deficient SDH function. Inclusion of patients with a normally functioning SDH complex (i.e., without hyperexpression of IGF-1R) could be an explanation for these rather disappointing results.

\section{Role of Surgery in Metastatic Patients}

In the French BFR14 trial, interruption of imatinib treatment in patients with metastatic GISTs was generally followed by rapid disease progression, even in patients who had complete tumor remission at the time when imatinib was stopped. Notably, some of these had achieved complete remission by surgical removal of all tumors (primary and metastatic) and presented with new lesions soon after imatinib withdrawal [84, 85]. These observations indicate that resection of metastatic disease in GISTs, in contrast to metastatic colorectal cancer, is generally not curative and must rather be considered as a debulking procedure. Primary surgery of metastatic GISTs is therefore not recommended and patients should undergo upfront TKI therapy [92], even if the disease is technically resectable. However, as the vast majority of metastatic GIST patients eventually develop secondary mutations making them resistant to imatinib, there may be a rationale for surgery in resectable patients who achieve disease stabilization, the aim being to decrease the likelihood that secondary mutations occur anywhere in the tumor. Moreover, as secondary resistance often develops in a focal manner, resulting in some lesions progressing while the majority is still under control with imatinib, another possible approach is to selectively remove the progressing lesions, which would ideally be able to postpone the need for second-line treatment if only lesions still responding to imatinib are left behind. While these approaches clearly appear to make sense, they have so far not been underscored by sufficient data. A prospective trial randomizing patients with metastatic GISTs who responded to imatinib to either continuation of imatinib therapy or debulking surgery at the time of best response (EORTC Soft Tissue and Bone Sarcoma Group 62063) was initiated in 2009 but had to be closed due to poor accrual in 2011. In a retrospective study, 80 patients treated with imatinib who either underwent debulking surgery at the time of best imatinib response or selective removal of progressing lesions in the case of focal progression were analyzed [93]. In the latter group, median progression-free survival following surgery (while imatinib was continued) was 8 months, meaning that surgery was able to postpone the need for second-line therapy by this period. In patients in whom focally progressing lesions are easily resectable, surgery may therefore be considered, as has also been acknowledged by current ESMO guidelines [70]. In the aforementioned study, progression-free survival was still substantially better in patients who underwent surgery of all residual disease before progression occurred (median progression-free survival not reached at median follow-up of 31 months); however, as these were retrospective data, these results are likely biased. However, if responding lesions can be removed without major functional impairment and with low risk of morbidity, surgery may be considered in this situation after shared decision-making with the patient.

\section{Other Treatments}

Since surgery for metastatic GISTs usually does not cure the patients and the evidence demonstrating its benefit is limited, maximum emphasis must be put on the safety of any intervention that these patients are submitted to. Locally ablative or locoregional therapies are in use in a variety of tumors, including primary and secondary liver neoplasms, and may constitute a less invasive modality for tumor debulking in this disease. Radiofrequency ablation [94, 95], transarterial chemoembolization [96, 97] and transarterial yttrium-90 radioembolization $[98,99]$ have all been used in patients with metastatic GISTs. As with 
surgery, data regarding local interventional treatments are retrospective and based on limited patient numbers. So far, any local treatment (including surgery) in metastatic GISTs must be considered as experimental and the appropriate modality must be chosen on an individual basis, taking into account both efficacy and safety concerns.

\section{Conclusions}

Although a relatively rare tumor entity, GISTs are the most frequently diagnosed mesenchymal neoplasm of the gastrointestinal tract. Their clinical and molecular characterization continues to evolve, extending the data foundation on which treatment decisions are made and new drugs are developed. Still, prediction of benign or malignant behavior of an individual GIST relies on empirically established scoring systems. Since data accumulated in the imatinib era suggest that malignant potential may be a constitutive quality of some GISTs rather than a feature acquired by the tumor during disease progression, some patients may require prolonged anti-tumor treatment even after complete surgical removal of their disease. Therefore, more accurate differentiation between benign and malignant GISTs is needed. Development of new targeted drugs for use in patients whose GISTs are either primarily resistant to established TKIs or acquire resistance during treatment is an ongoing process, with several new targets currently under investigation. As progression in metastatic GISTs often occurs in a focal manner, local (surgical or interventional) treatment approaches in metastatic GISTs are expected to yield substantial benefit; however, creating solid evidence supporting their use has proved challenging. In a time where the distinction between curative and palliative treatment approaches is becoming less dogmatic in many fields of oncology, local therapies will continue to be used on an individual basis in metastatic GISTs. As long as their benefit is not formally proven, however, these treatments must be employed with extreme caution and a clear focus on patient safety.

\section{References}

1 Mazur MT, Clark HB: Gastric stromal tumors. Reappraisal of histogenesis. Am J Surg Pathol 1983;7:507-519.

2 Hirota S, Isozaki K, Moriyama Y, Hashimoto K, Nishida T, Ishiguro S, Kawano K, Hanada M, Kurata A, Takeda M, Muhammad Tunio G, Matsuzawa Y, Kanakura Y, Shinomura Y, Kitamura Y: Gain-of-function mutations of c-kit in human gastrointestinal stromal tumors. Science 1998;279:577-580.

3 Kindblom LG, Remotti HE, Aldenborg F, Meis-Kindblom JM: Gastrointestinal pacemaker cell tumor (GIPACT): gastrointestinal stromal tumors show phenotypic characteristics of the interstitial cells of Cajal. Am J Pathol 1998;152:1259-1269.

4 Joensuu H, Roberts PJ, Sarlomo-Rikala M, Andersson LC, Tervahartiala P, Tuveson D, Silberman S, Capdeville R, Dimitrijevic S, Druker B, Demetri GD: Effect of the tyrosine kinase inhibitor STI571 in a patient with a metastatic gastrointestinal stromal tumor. N Engl J Med 2001;344:1052-1056.

5 Antonescu CR, Besmer P, Guo T, Arkun K, Hom G, Koryotowski B, Leversha MA, Jeffrey PD, Desantis D, Singer S, Brennan MF, Maki RG, DeMatteo RP: Acquired resistance to imatinib in gastrointestinal stromal tumor occurs through secondary gene mutation. Clin Cancer Res 2005;11:4182-4190.

6 Gounder MM, Maki RG: Molecular basis for primary and secondary tyrosine kinase inhibitor resistance in gastrointestinal stromal tumor. Cancer Chemother Pharmacol 2011;67(suppl 1):S25-S43.

7 Tryggvason G, Gíslason HG, Magnússon MK, Jónasson JG: Gastrointestinal stromal tumors in Iceland, 19902003: the Icelandic GIST study, a population-based incidence and pathologic risk stratification study. Int J Cancer 2005;117:289-293.

8 Nilsson B, Bümming P, Meis-Kindblom JM, Odén A, Dortok A, Gustavsson B, Sablinska K, Kindblom L: Gastrointestinal stromal tumors: the incidence, prevalence, clinical course, and prognostication in the preimatinib mesylate era - a population-based study in western Sweden. Cancer 2005;103:821-829.

9 Ferraro D, Zalcberg J: Regorafenib in gastrointestinal stromal tumors: clinical evidence and place in therapy. Ther Adv Med Oncol 2014;6:222-228. 
10 Agaimy A, Wünsch PH, Hofstaedter F, Blaszyk H, Rümmele P, Gaumann A, Dietmaier W, Hartmann A: Minute gastric sclerosing stromal tumors (GIST tumorlets) are common in adults and frequently show c-KIT mutations. Am J Surg Pathol 2007;31:113-120.

11 Abraham SC, Krasinskas AM, Hofstetter WL, Swisher SG, Wu T: 'Seedling' mesenchymal tumors (gastrointestinal stromal tumors and leiomyomas) are common incidental tumors of the esophagogastric junction. Am J Surg Pathol 2007;31:1629-1635.

12 Janeway KA, Kim SY, Lodish M, Nosé V, Rustin P, Gaal J, Dahia PL, Liegl B, Ball ER, Raygada M, Lai AH, Kelly L, Hornick JL, O'Sullivan M, de Krijger RR, Dinjens WN, Demetri GD, Antonescu CR, Fletcher JA, Helman L, Stratakis CA: Defects in succinate dehydrogenase in gastrointestinal stromal tumors lacking KIT and PDGFRA mutations. Proc Natl Acad Sci USA 2011;108:314-318.

13 Miettinen M, Wang Z, Sarlomo-Rikala M, Osuch C, Rutkowski P, Lasota J: Succinate dehydrogenase-deficient GISTs: a clinicopathologic, immunohistochemical, and molecular genetic study of 66 gastric GISTs with predilection to young age. Am J Surg Pathol 2011;35:1712-1721.

14 Agaimy A, Wünsch PH: Lymph node metastasis in gastrointestinal stromal tumours (GIST) occurs preferentially in young patients $<$ or $=40$ years: an overview based on our case material and the literature. Langenbecks Arch Surg 2009;394:375-381.

15 Nishida T, Hirota S, Taniguchi M, Hashimoto K, Isozaki K, Nakamura H, Kanakura Y, Tanaka T, Takabayashi A, Matsuda H, Kitamura Y: Familial gastrointestinal stromal tumours with germline mutation of the KIT gene. Nat Genet 1998;19:323-324.

16 Li FP, Fletcher JA, Heinrich MC, Garber JE, Sallan SE, Curiel-Lewandrowski C, Duensing A, van de Rijn M, Schnipper LE, Demetri GD: Familial gastrointestinal stromal tumor syndrome: phenotypic and molecular features in a kindred. J Clin Oncol 2005;23:2735-2743.

17 Chompret A, Kannengiesser C, Barrois M, Terrier P, Dahan P, Tursz T, Lenoir GM, Bressac-De Paillerets B: PDGFRA germline mutation in a family with multiple cases of gastrointestinal stromal tumor. Gastroenterology 2004;126:318-321.

18 Yantiss RK, Rosenberg AE, Sarran L, Besmer P, Antonescu CR: Multiple gastrointestinal stromal tumors in type I neurofibromatosis: a pathologic and molecular study. Mod Pathol 2005;18:475-484.

19 Takazawa Y, Sakurai S, Sakuma Y, Ikeda T, Yamaguchi J, Hashizume Y, Yokoyama S, Motegi A, Fukayama M: Gastrointestinal stromal tumors of neurofibromatosis type I (von Recklinghausen's disease). Am J Surg Pathol 2005;29:755-763.

20 Zagorowicz ES, Pietrzak AM, Wronska E, Pachlewski J, Rutkowski P, Kraszewska E, Regula J: Small bowel tumors detected and missed during capsule endoscopy: single center experience. World J Gastroenterol 2013; 19:9043-9048.

21 Nakatani M, Fujiwara Y, Nagami Y, Sugimori S, Kameda N, Machida H, Okazaki H, Yamagami H, Tanigawa T, Watanabe K, Watanabe T, Tominaga K, Noda E, Maeda K, Ohsawa M, Wakasa K, Hirakawa K, Arakawa T: The usefulness of double-balloon enteroscopy in gastrointestinal stromal tumors of the small bowel with obscure gastrointestinal bleeding. Int Med 2012;51:2675-2682.

22 Ling J, Lamsen M, Coron R, Deliana D, Siddiqui S, Rangraj M, Jesmajian S: Recurrent lower gastrointestinal bleeding: ileal GIST diagnosed by video capsule endoscopy - a case report and literature review. Case Rep Gastrointest Med 2013;2013:285457.

23 Urgesi R, Riccioni ME, Bizzotto A, Cianci R, Spada C, Pelecca G, Ricci R, Ricci RM, Costamagna G: Increased diagnostic yield of small bowel tumors with PillCam: the role of capsule endoscopy in the diagnosis and treatment of gastrointestinal stromal tumors (GISTs). Italian single-center experience. Tumori 2012;98:357-363.

24 Winant AJ, Gollub MJ, Shia J, Antonescu C, Bains MS, Levine MS: Imaging and clinicopathologic features of esophageal gastrointestinal stromal tumors. AJR Am J Roentgenol 2014;203:306-314.

25 Choi YR, Kim SH, Kim S, Shin C, Kim HJ, Kim SH, Han JK, Choi BI: Differentiation of large ( $\geq 5 \mathrm{~cm}$ ) gastrointestinal stromal tumors from benign subepithelial tumors in the stomach: radiologists' performance using CT. Eur J Radiol 2014;83:250-260.

26 Yu MH, Lee JM, Baek JH, Han JK, Choi B: MRI features of gastrointestinal stromal tumors. AJR Am J Roentgenol 2014;203:980-991.

27 Zhou HY, Zhang XM, Zeng NL, Jian SH, Tang W: Use of conventional MR imaging and diffusion-weighted imaging for evaluating the risk grade of gastrointestinal stromal tumors. J Magn Reson Imaging 2012;36: 1395-1401.

28 Ito H, Inoue H, Ryozawa S, Ikeda H, Odaka N, Eleftheriadis N, Maselli R, Sando N, Kimura S, Kudo SE: Fineneedle aspiration biopsy and endoscopic ultrasound for pretreatment pathological diagnosis of gastric gastrointestinal stromal tumors. Gastroenterol Res Pract 2012;2012:139083.

29 Eckardt AJ, Adler A, Gomes EM, Jenssen C, Siebert C, Gottschalk U, Koch M, Röcken C, Rösch T: Endosonographic large-bore biopsy of gastric subepithelial tumors: a prospective multicenter study. Eur J Gastroenterol Hepatol 2012;24:1135-1144.

30 DeWitt J, Emerson RE, Sherman S, Al-Haddad M, McHenry L, Cote GA, Leblanc JK: Endoscopic ultrasoundguided Trucut biopsy of gastrointestinal mesenchymal tumor. Surg Endosc 2011;25:2192-2202.

31 Yeh C, Pan K, Chu S, Chen C, Hsu M, Hung C, Tseng J: Safety and efficacy of image-guided percutaneous biopsies in the diagnosis of gastrointestinal stromal tumors. Clin Imaging 2012;36:19-23. 
32 Tombesi P, Postorivo S, Catellani M, Tassinari D, Abbasciano V, Sartori S: Percutaneous ultrasonographyguided core needle biopsy of gastrointestinal lesions: what's its actual role in clinical practice? A retrospective study for safety and effectiveness. Ultraschall Med 2011;32(suppl 1):S62-S67.

33 Ronellenfitsch U, Wängler B, Niedermoser S, Dimitrakopoulou-Strauss A, Hohenberger P: Bedeutung der PET für die Chirurgie des gastrointestinalen Stromatumors. Chirurg 2014;85:493-499.

34 Sogawa C, Tsuji AB, Sudo H, Sugyo A, Yoshida C, Odaka K, Uehara T, Arano Y, Koizumi M, Saga T: C-kit-targeted imaging of gastrointestinal stromal tumor using radiolabeled anti-c-kit monoclonal antibody in a mouse tumor model. Nucl Med Biol 2010;37:179-187.

35 Treglia G, Mirk P, Stefanelli A, Rufini V, Giordano A, Bonomo L: 18F-fluorodeoxyglucose positron emission tomography in evaluating treatment response to imatinib or other drugs in gastrointestinal stromal tumors: a systematic review. Clin Imaging 2012;36:167-175.

36 Joensuu H, Vehtari A, Riihimäki J, Nishida T, Steigen SE, Brabec P, Plank L, Nilsson B, Cirilli C, Braconi C, Bordoni A, Magnusson MK, Linke Z, Sufliarsky J, Federico M, Jonasson JG, Dei Tos AP, Rutkowski P: Risk of recurrence of gastrointestinal stromal tumour after surgery: an analysis of pooled population-based cohorts. Lancet Oncol 2012;13:265-274.

37 McCarter MD, Antonescu CR, Ballman KV, Maki RG, Pisters PW, Demetri GD, Blanke CD, von Mehren M, Brennan MF, McCall L, Ota DM, DeMatteo RP; American College of Surgeons Oncology Group (ACOSOG) Intergroup Adjuvant GIST Study Team: Microscopically positive margins for primary gastrointestinal stromal tumors: analysis of risk factors and tumor recurrence. J Am Coll Surg 2012;215:53-59.

38 Catena F, Di Battista M, Ansaloni L, Pantaleo M, Fusaroli P, Di Scioscio V, Santini D, Nannini M, Saponara M, Ponti G, Persiani R, Delrio P, Coccolini F, Di Saverio S, Biasco G, Lazzareschi D, Pinna A: Microscopic margins of resection influence primary gastrointestinal stromal tumor survival. Onkologie 2012;35:645-648.

39 Fiore M, Palassini E, Fumagalli E, Pilotti S, Tamborini E, Stacchiotti S, Pennacchioli E, Casali PG, Gronchi A: Preoperative imatinib mesylate for unresectable or locally advanced primary gastrointestinal stromal tumors (GIST). Eur J Surg Oncol 2009;35:739-745.

40 Rutkowski P, Gronchi A, Hohenberger P, Bonvalot S, Schöffski P, Bauer S, Fumagalli E, Nyckowski P, Nguyen BP, Kerst JM, Fiore M, Bylina E, Hoiczyk M, Cats A, Casali PG, Le Cesne A, Treckmann J, Stoeckle E, de Wilt JH, Sleijfer S, Tielen R, van der Graaf W, Verhoef C, van Coevorden F: Neoadjuvant imatinib in locally advanced gastrointestinal stromal tumors (GIST): the EORTC STBSG experience. Ann Surg Oncol 2013;20:2937-2943.

41 Tokunaga M, Ohyama S, Hiki N, Fukunaga T, Yamamoto N, Yamaguchi T: Incidence and prognostic value of lymph node metastasis on c-Kit-positive gastrointestinal stromal tumors of the stomach. Hepatogastroenterology 2011;58:1224-1228.

42 Gervaz P, Huber O, Morel P: Surgical management of gastrointestinal stromal tumours. Br J Surg 2009;96: 567-578.

43 Hsiao CY, Yang CY, Lai IR, Chen CN, Lin MT: Laparoscopic resection for large gastric gastrointestinal stromal tumor (GIST): intermediate follow-up results. Surg Endosc 2015;29:868-873.

44 Correa-Cote J, Morales-Uribe C, Sanabria A: Laparoscopic management of gastric gastrointestinal stromal tumors. World J Gastrointest Endosc 2014;6:296-303.

45 Nozawa H, Kanazawa T, Tanaka T, Takahashi M, Ishihara S, Sunami E, Kitayama J, Ikemura M, Komuro I, Watanabe T: Laparoscopic resection of a gastrointestinal stromal tumor of the lower rectum in a patient with coronary artery disease following long-term neoadjuvant imatinib treatment and anticoagulation therapy. World J Surg Oncol 2014;12:211-215.

46 Masoni L, Gentili I, Maglio R, Meucci M, D’Ambra G, Di Giulio E, Di Nardo G, Corleto VD: Laparoscopic resection of large gastric GISTs: feasibility and long-term results. Surg Endosc 2014;28:2905-2910.

47 Photi ES, Igali L, Cheong EC, Clark A, Lewis MP: Long-term outcomes and recurrence patterns in upper gastrointestinal tract gastrointestinal stromal tumours (GISTs) treated by minimally invasive surgery. Dig Surg 2014;31:185-189.

48 Chen QL, Pan Y, Cai JQ, Wu D, Chen K, Mou YP: Laparoscopic versus open resection for gastric gastrointestinal stromal tumors: an updated systematic review and meta-analysis. World J Surg Oncol 2014;12:206-218.

49 Hohenberger P, Ronellenfitsch U, Oladeji O, Pink D, Ströbel P, Wardelmann E, Reichardt P: Pattern of recurrence in patients with ruptured primary gastrointestinal stromal tumour. Br J Surg 2010;97:1854-1859.

50 Lin J, Huang C, Zheng C, Li P, Xie J, Wang J, Lu J: Laparoscopic versus open gastric resection for larger than $5 \mathrm{~cm}$ primary gastric gastrointestinal stromal tumors (GIST): a size-matched comparison. Surg Endosc 2014; 28:2577-2583.

51 Huang W, Feng C, Lai H, Yu C, Chou J, Peng C, Yang M, Chiang I: Endoscopic ligation and resection for the treatment of small EUS-suspected gastric GI stromal tumors. Gastrointest Endosc 2010;71:1076-1081.

52 Katoh T, Itoh Y, Mohri T, Suzuki H: Endoscopic enucleation of gastrointestinal stromal tumors of the stomach: report of five cases. World J Gastroenterol 2008;14:2609-2611.

53 Liu B, Song J, Qu B, Wen J, Yin J, Liu W: Endoscopic muscularis dissection for upper gastrointestinal subepithelial tumors originating from the muscularis propria. Surg Endosc 2012;26:3141-3148.

54 Zhou P, Yao L, Qin X, Cai M, Xu M, Zhong Y, Chen W, Zhang Y, Qin W, Hu J, Liu J: Endoscopic full-thickness resection without laparoscopic assistance for gastric submucosal tumors originated from the muscularis propria. Surg Endosc 2011;25:2926-2931.

55 Schmidt A, Bauder M, Riecken B, von Renteln D, Muehleisen H, Caca K: Endoscopic full-thickness resection of gastric subepithelial tumors: a single-center series. Endoscopy 2015;47:154-158. 
Garlipp and Bruns: State of the Art in the Treatment of Gastrointestinal Stromal Tumors

56 Duek S, Kluger Y, Grunner S, Weinbroum AA, Khoury W: Transanal endoscopic microsurgery for the resection of submucosal and retrorectal tumors. Surg Laparosc Endosc Percutan Tech 2013;23:66-68.

57 Khoury W, Igov I, Issa N, Gimelfarb Y, Duek SD: Transanal endoscopic microsurgery for upper rectal tumors. Surg Endosc 2014;28:2066-2071.

58 Allaix ME, Arezzo A, Caldart M, Festa F, Morino M: Transanal endoscopic microsurgery for rectal neoplasms: experience of 300 consecutive cases. Dis Colon Rectum 2009;52:1831-1836.

59 Demetri GD, von Mehren M, Blanke CD, Van den Abbeele AD, Eisenberg B, Roberts PJ, Heinrich MC, Tuveson DA, Singer S, Janicek M, Fletcher JA, Silverman SG, Silberman SL, Capdeville R, Kiese B, Peng B, Dimitrijevic S, Druker BJ, Corless C, Fletcher CD, Joensuu H: Efficacy and safety of imatinib mesylate in advanced gastrointestinal stromal tumors. New Engl J Med 2002;347:472-480.

60 Tielen R, Verhoef C, van Coevorden F, Gelderblom H, Sleijfer S, Hartgrink HH, Bonenkamp JJ, van der Graaf WTA, de Wilt JHW: Surgical treatment of locally advanced, non-metastatic, gastrointestinal stromal tumours after treatment with imatinib. Eur J Surg Oncol 2013;39:150-155.

61 Hohenberger P, Langer C, Wendtner CM, Hohenberger W, Pustowka A, Wardelmann E, Andre E, Licht T: Neoadjuvant treatment of locally advanced GIST: results of APOLLON, a prospective, open label phase II study in KIT- or PDGFRA-positive tumors. J Clin Oncol 2012;30(suppl):abstr 10031.

62 Jakob J, Mussi C, Ronellenfitsch U, Wardelmann E, Negri T, Gronchi A, Hohenberger P: Gastrointestinal stromal tumor of the rectum: results of surgical and multimodality therapy in the era of imatinib. Ann Surg Oncol 2013; 20:586-592.

63 Stroobants S, Goeminne J, Seegers M, Dimitrijevic S, Dupont P, Nuyts J, Martens M, van den Borne B, Cole P, Sciot R, Dumez H, Silberman S, Mortelmans L, van Oosterom A: 18FDG-positron emission tomography for the early prediction of response in advanced soft tissue sarcoma treated with imatinib mesylate (Glivec ${ }^{\circledR}$ ). Eur J Cancer 2003;39:2012-2020.

64 Gayed I, Vu T, Iyer R, Johnson M, Macapinlac H, Swanston N, Podoloff D: The role of 18F-FDG PET in staging and early prediction of response to therapy of recurrent gastrointestinal stromal tumors. J Nucl Med 2004;45:17-21.

65 Van den Abbeele AD, Gatsonis C, de Vries DJ, Melenevsky Y, Szot-Barnes A, Yap JT, Godwin AK, Rink L, Huang M, Blevins M, Sicks J, Eisenberg B, Siegel BA: ACRIN 6665/RTOG 0132 phase II trial of neoadjuvant imatinib mesylate for operable malignant gastrointestinal stromal tumor: monitoring with 18F-FDG PET and correlation with genotype and GLUT4 expression. J Nucl Med 2012;53:567-574.

66 DeMatteo RP, Ballman KV, Antonescu CR, Maki RG, Pisters PW, Demetri GD, Blackstein ME, Blanke CD, von Mehren M, Brennan MF, Patel S, McCarter MD, Polikoff JA, Tan BR, Owzar K: Adjuvant imatinib mesylate after resection of localised, primary gastrointestinal stromal tumour: a randomised, double-blind, placebocontrolled trial. Lancet 2009;373:1097-1104.

67 Miettinen M, Lasota J: Gastrointestinal stromal tumors: review on morphology, molecular pathology, prognosis, and differential diagnosis. Arch Pathol Lab Med 2006;130:1466-1478.

68 Joensuu H: Risk stratification of patients diagnosed with gastrointestinal stromal tumor. Hum Pathol 2008; 39:1411-1419.

69 Joensuu H, Eriksson M, Sundby Hall K, Hartmann JT, Pink D, Schütte J, Ramadori G, Hohenberger P, Duyster J, Al-Batran S, Schlemmer M, Bauer S, Wardelmann E, Sarlomo-Rikala M, Nilsson B, Sihto H, Monge OR, Bono P, Kallio R, Vehtari A, Leinonen M, Alvegård T, Reichardt P: One vs three years of adjuvant imatinib for operable gastrointestinal stromal tumor: a randomized trial. JAMA 2012;307:1265-1272.

70 ESMO/European Sarcoma Network Working Group: Gastrointestinal stromal tumors: ESMO Clinical Practice Guidelines for diagnosis, treatment and follow-up. Ann Oncol 2014;25(suppl 3):iii21-iii26.

71 von Mehren M, Randall RL, Benjamin RS, Boles S, Bui MM, Casper ES, Conrad EU, DeLaney TF, Ganjoo KN, George S, Gonzalez RJ, Heslin MJ, Kane JM, Mayerson J, McGarry SV, Meyer C, O’Donnell RJ, Pappo AS, Paz IB, Pfeifer JD, Riedel RF, Schuetze S, Schupak KD, Schwartz HS, Van Tine BA, Wayne JD, Bergman MA, Sundar H: Gastrointestinal stromal tumors, version 2.2014. J Natl Compr Canc Netw 2014;12:853-862.

72 Cassier PA, Fumagalli E, Rutkowski P, Schöffski P, van Glabbeke M, Debiec-Rychter M, Emile J, Duffaud F, Martin-Broto J, Landi B, Adenis A, Bertucci F, Bompas E, Bouché O, Leyvraz S, Judson I, Verweij J, Casali P, Blay J, Hohenberger P: Outcome of patients with platelet-derived growth factor receptor alpha-mutated gastrointestinal stromal tumors in the tyrosine kinase inhibitor era. Clin Cancer Res 2012;18:4458-4464.

73 Corless CL, Ballman KV, Antonescu CR, Kolesnikova V, Maki RG, Pisters PW, Blackstein ME, Blanke CD, Demetri GD, Heinrich MC, von Mehren M, Patel S, McCarter MD, Owzar K, DeMatteo RP: Pathologic and molecular features correlate with long-term outcome after adjuvant therapy of resected primary GI stromal tumor: the ACOSOG Z9001 trial. J Clin Oncol 2014;32:1563-1570.

74 Gastrointestinal Stromal Tumors Meta-Analysis Group (MetaGIST): Comparison of two doses of imatinib for the treatment of unresectable or metastatic gastrointestinal stromal tumors: a meta-analysis of 1,640 patients. J Clin Oncol 2010;28:1247-1253.

75 Edmonson JH, Marks RS, Buckner JC, Mahoney MR: Contrast of response to dacarbazine, mitomycin, doxorubicin, and cisplatin (DMAP) plus GM-CSF between patients with advanced malignant gastrointestinal stromal tumors and patients with other advanced leiomyosarcomas. Cancer Invest 2002;20:605-612.

76 Choi H, Charnsangavej C, Faria SC, Macapinlac HA, Burgess MA, Patel SR, Chen LL, Podoloff DA, Benjamin RS: Correlation of computed tomography and positron emission tomography in patients with metastatic gastrointestinal stromal tumor treated at a single institution with imatinib mesylate: proposal of new computed tomography response criteria. J Clin Oncol 2007;25:1753-1759. 
77 Chen LL, Trent JC, Wu EF, Fuller GN, Ramdas L, Zhang W, Raymond AK, Prieto VG, Oyedeji CO, Hunt KK, Pollock RE, Feig BW, Hayes KJ, Choi H, Macapinlac HA, Hittelman W, Velasco MA, Patel S, Burgess MA, Benjamin RS, Frazier ML: A missense mutation in KIT kinase domain 1 correlates with imatinib resistance in gastrointestinal stromal tumors. Cancer Res 2004;64:5913-5919.

78 Heinrich MC, Corless CL, Blanke CD, Demetri GD, Joensuu H, Roberts PJ, Eisenberg BL, von Mehren M, Fletcher CD, Sandau K, McDougall K, Ou W, Chen C, Fletcher JA: Molecular correlates of imatinib resistance in gastrointestinal stromal tumors. J Clin Oncol 2006;24:4764-4774.

79 Hislop J, Mowatt G, Sharma P, Fraser C, Elders A, Jenkinson D, Vale L, Petty R: Systematic review of escalated imatinib doses compared with sunitinib or best supportive care, for the treatment of people with unresectable/metastatic gastrointestinal stromal tumours whose disease has progressed on the standard imatinib dose. J Gastrointest Cancer 2012;43:168-176.

80 Demetri GD, van Oosterom AT, Garrett CR, Blackstein ME, Shah MH, Verweij J, McArthur G, Judson IR, Heinrich MC, Morgan JA, Desai J, Fletcher CD, George S, Bello CL, Huang X, Baum CM, Casali PG: Efficacy and safety of sunitinib in patients with advanced gastrointestinal stromal tumour after failure of imatinib: a randomised controlled trial. Lancet 2006;368:1329-1338.

81 Adenis A, Blay J, Bui-Nguyen B, Bouché O, Bertucci F, Isambert N, Bompas E, Chaigneau L, Domont J, RayCoquard I, Blésius A, Van Tine BA, Bulusu VR, Dubreuil P, Mansfield CD, Acin Y, Moussy A, Hermine O, Le Cesne A: Masitinib in advanced gastrointestinal stromal tumor (GIST) after failure of imatinib: a randomized controlled open-label trial. Ann Oncol 2014;25:1762-1769.

82 Kang Y, Ryu M, Yoo C, Ryoo B, Kim HJ, Lee JJ, Nam B, Ramaiya N, Jagannathan J, Demetri GD: Resumption of imatinib to control metastatic or unresectable gastrointestinal stromal tumours after failure of imatinib and sunitinib (RIGHT): a randomised, placebo-controlled, phase 3 trial. Lancet Oncol 2013;14:1175-1182.

83 Demetri GD, Reichardt P, Kang YK, Blay JY, Rutkowski P, Gelderblom H, Hohenberger P, Leahy M, von Mehren M, Joensuu H, Badalamenti G, Blackstein M, Le Cesne A, Schöffski P, Maki RG, Bauer S, Nguyen BB, Xu J, Nishida T, Chung J, Kappeler C, Kuss I, Laurent D, Casali PG; GRID study investigators: Efficacy and safety of regorafenib for advanced gastrointestinal stromal tumours after failure of imatinib and sunitinib (GRID): an international, multicentre, randomised, placebo-controlled, phase 3 trial. Lancet 2013;381:295-302.

84 Blay J, Le Cesne A, Ray-Coquard I, Bui B, Duffaud F, Delbaldo C, Adenis A, Viens P, Rios M, Bompas E, Cupissol D, Guillemet C, Kerbrat P, Fayette J, Chabaud S, Berthaud P, Perol D: Prospective multicentric randomized phase III study of imatinib in patients with advanced gastrointestinal stromal tumors comparing interruption versus continuation of treatment beyond 1 year: the French Sarcoma Group. J Clin Oncol 2007;25:1107-1113.

85 Le Cesne A, Ray-Coquard I, Bui BN, Adenis A, Rios M, Bertucci F, Duffaud F, Chevreau C, Cupissol D, Cioffi A, Emile J, Chabaud S, Pérol D, Blay J: Discontinuation of imatinib in patients with advanced gastrointestinal stromal tumours after 3 years of treatment: an open-label multicentre randomised phase 3 trial. Lancet Oncol 2010;11:942-949.

86 Ray-Coquard IL, Bin Bui N, Adenis A, Rios M Sr, Bertucci F, Chabaud S, Perol D, Blay J, Le Cesne A: Risk of relapse with imatinib (IM) discontinuation at 5 years in advanced GIST patients: Results of the prospective BFR14 randomized phase III study comparing interruption versus continuation of IM at 5 years of treatment: a French Sarcoma Group study. J Clin Oncol 2010;28(suppl):abstr 10032.

87 Patrikidou A, Chabaud S, Ray-Coquard I, Bui BN, Adenis A, Rios M, Bertucci F, Duffaud F, Chevreau C, Cupissol D, Domont J, Pérol D, Blay JY, Le Cesne A: Influence of imatinib interruption and rechallenge on the residual disease in patients with advanced GIST: results of the BFR14 prospective French Sarcoma Group randomised, phase III trial. Ann Oncol 2013;24:1087-1093.

88 Garner AP, Gozgit JM, Anjum R, Vodala S, Schrock A, Zhou T, Serrano C, Eilers G, Zhu M, Ketzer J, Wardwell S, Ning Y, Song Y, Kohlmann A, Wang F, Clackson T, Heinrich MC, Fletcher JA, Bauer S, Rivera VM: Ponatinib inhibits polyclonal drug-resistant KIT oncoproteins and shows therapeutic potential in heavily pretreated gastrointestinal stromal tumor (GIST) patients. Clin Cancer Res 2014;20:5745-5755.

89 Heinrich MC, von Mehren M, Demetri D, Fletcher JA, Sun J, Hodgson JG, Rivera VM, Turner CD, George S: A phase 2 study of ponatinib in patients (pts) with advanced gastrointestinal stromal tumors (GIST) after failure of tyrosine kinase inhibitor (TKI) therapy: initial report. J Clin Oncol 2014;32(suppl):abstr 10506.

90 Heinrich MC, Griffith D, McKinley A, Patterson J, Presnell A, Ramachandran A, Debiec-Rychter M: Crenolanib inhibits the drug-resistant PDGFRA D842V mutation associated with imatinib-resistant gastrointestinal stromal tumors. Clin Cancer Res 2012;18:4375-4384.

91 von Mehren M, George S, Heinrich MC, Schuetze S, Belinsky MG, Janeway KA, Rink L, Ganjoo KN, Yu JQ, Yap JT, Wright JJ, van den Abbeele AD: Results of SARC 022, a phase II multicenter study of linsitinib in pediatric and adult wild-type (WT) gastrointestinal stromal tumors (GIST). J Clin Oncol 2014;32(suppl):abstr 10507.

92 An HJ, Ryu M, Ryoo B, Sohn BS, Kim K, Oh ST, Yu CS, Yook JH, Kim BS, Kang Y: The effects of surgical cytoreduction prior to imatinib therapy on the prognosis of patients with advanced GIST. Ann Surg Oncol 2013;20: 4212-4218.

93 Mussi C, Ronellenfitsch U, Jakob J, Tamborini E, Reichardt P, Casali PG, Fiore M, Hohenberger P, Gronchi A: Post-imatinib surgery in advanced/metastatic GIST: is it worthwhile in all patients? Ann Oncol 2010;21:403408.

94 Hakimé A, Le Cesne A, Deschamps F, Farouil G, Boudabous S, Aupérin A, Domont J, DeBaere T: A role for adjuvant RFA in managing hepatic metastases from gastrointestinal stromal tumors (GIST) after treatment with targeted systemic therapy using kinase inhibitors. Cardiovasc Intervent Radiol 2014;37:132-139. 
95 Yamanaka T, Takaki H, Nakatsuka A, Uraki J, Fujimori M, Hasegawa T, Sakuma H, Yamakado K: Radiofrequency ablation for liver metastasis from gastrointestinal stromal tumor. J Vasc Interv Radiol 2013;24:341-346.

96 Takaki H, Litchman T, Covey A, Cornelis F, Maybody M, Getrajdman GI, Sofocleous CT, Brown KT, Solomon SB, Alago W, Erinjeri JP: Hepatic artery embolization for liver metastasis of gastrointestinal stromal tumor following imatinib and sunitinib therapy. J Gastrointest Cancer 2014;45:494-499.

97 Cao G, Zhu X, Li J, Shen L, Yang R, Chen H, Wang X, Gao S, Xu H, Zhu L, Liu P, Guo J: A comparative study between Embosphere ${ }^{\circledR}$ and conventional transcatheter arterial chemoembolization for treatment of unresectable liver metastasis from GIST. Chin J Cancer Res 2014;26:124-131.

98 Wright CL, Werner JD, Tran JM, Gates VL, Rikabi AA, Shah MH, Salem R: Radiation pneumonitis following yttrium-90 radioembolization: case report and literature review. J Vasc Interv Radiol 2012;23:669-674.

99 Kao Y, Steinberg JD, Tay Y, Lim GK, Yan J, Townsend DW, Budgeon CA, Boucek JA, Francis RJ, Cheo TS, Burgmans MC, Irani FG, Lo RH, Tay K, Tan B, Chow PK, Satchithanantham S, Tan AE, Ng DC, Goh AS: Post-radioembolization yttrium-90 PET/CT - part 2: dose-response and tumor predictive dosimetry for resin microspheres. EJNMMI Res 2013;3:57. 